\title{
Model Numerik 1-Dimensi Aliran di Sungai dengan Metode Differensi Hingga Skema Staggered Grid, Study Kasus Kali Kemuning-Sampang Madura
}

\author{
Suharjoko \\ Staft Pengajar Program Studi D-III Teknik Sipil FTSP \\ email: suharjoko_hydro@ce.its.ac.id; suharjoko_hydro@yahoo.com
}

\begin{abstract}
ABSTRAK
Pada suatu sungai dimana penampangnya tidak seragam ( non-uniform ) demikian pula kemiringan dasar sungainya, kondisi inflow sungai sebagai batas hulu dan adanya pengaruh pasang surut di hilir sungai. Kondisi aliran di sungai yang demikian ini adalah aliran tak tunak dan tak seragam (unsteady non-uniform flow). Maka penyelesaian perhitungan aliran sungai demikian ini adalah menggunakan persamaan kontinuitas dan persamaan momentum. Namun kedua persamaan ini merupakan persamaan differential partial, sehingga dapat diselesaikan dengan metode numerik. Demikian halnya pada sungai Kali Kemuning Sampang-Madura, permasalahan yang terjadi di Kali Kemuning adalah kapasitas alirannya mengecil sehingga sering terjadi banjir di musim hujan. Persamaan kontinuitas dan persamaan momentum yang akan diselesaikan adalah persamaan 1-Dimensi aliran. Methode yang akan digunakan adalah metode differensi hingga skema Staggered Grid. Model hitungan ini diharapkan dapat menunjukkan / mensimulasikan fenomena aliran yang akan terjadi di sepanjang sungai dengan kondisi geometrinya, terutama kondisi geometri rencana. Methode numerik Skema Staggered Grid diharapkan dapat memberikan pemahaman kondisi aliran sungai. Pada kasus analisa rencana kapasitas normalisasi sungai Kali Kemuning, dimana direncanakan dua kemiringan dasar sungai, di hulu lo $=0,0004$, sedangkan di hilir lo =0,000199. Iebar sungai direncanakan non-uniform, dari hulu lebar sungai $=25 \mathrm{~m}$. kemudian ke hilir berangsur-angsur melebar $35 \mathrm{~m}$. kemudian $45 \mathrm{~m}$. dan sampai hilir melebar hingga $55 \mathrm{~m}$. Batas hilir pasang surut dengan tinggi $\mathrm{H}=2.00 \mathrm{~m}$. dan periode adalah $12 \mathrm{jam}$, batas hulu hydrograf banjir Kali Kemuning yaitu dengan puncak banjir sebesar $300 \mathrm{~m} 3 / \mathrm{dt}$. Hasil simulasi telah dapat menggambarkan dengan baik pemahaman kondisi aliran sungai dan muka air pada setiap jam di sepanjang sungai.
\end{abstract}

Kata Kunci: Unteady Flow, Staggered Grid.

\section{PENDAHULUAN}

\subsection{Latar Belakang}

Pada suatu sungai seperti pada umumnya sungai alam dimana penampangnya tidak seragam ( non-uniform ) dan aliran yang ada tidak tetap serta adanya pengaruh pasang surut di bagian hilir sungai (unsteady nonuniform flow), maka penyelesaian hitungan aliran sungai demikian ini, menggunakan persamaan kontinuitas dan persamaan momentum. Persamaan kontinuitas dan persamaan momentum itu adalah persamaan 1-Dimensi aliran. Namun ke dua persamaan ini merupakan persamaan differential partial sehingga hanya dapat diselesaikan dengan metode numerik. Methode yang akan digunakan adalah metode differensi hingga skema Staggered Grid. Penyelesaian ini diharapkan dapat memberikan simulasi kondisi (fenomena) aliran sungai yang akan terjadi.

Batas hulu sungai akan diberikan unsteady flow yaitu dalam bentuk hidrograf banjir, akibat kondisi batas hulu ini akan terjadi perpindahan puncak gelombang dari waktu ke waktu menuju ke hilir sungai, sehingga fenomena ini disebut pula perambatan banjir.

Berdasarkan hasil Studi Run-Off Sungai di Jawa Timur (2006), Studi Daya Rusak Air Kali Kemuning (2008), merupakan sungai yang dikatagorikan produktif penghasil bahan sedimen, disamping itu Kali Kemuning juga merupakan kali dengan run-off yang cukup 
besar dan melebihi kapasitas sungai yang ada. Sementara itu bagian hilir Kali Kemuning melalui jantung Kota Sampang dan sekaligus Kali Kemuning ini masih difungsikan sebagai pelabuhan dan alur pelayaran bagi perahu nelayan. Pada Gambar 1. dapat dilihat situasi Kali Kemuning dan Kota Sampang.

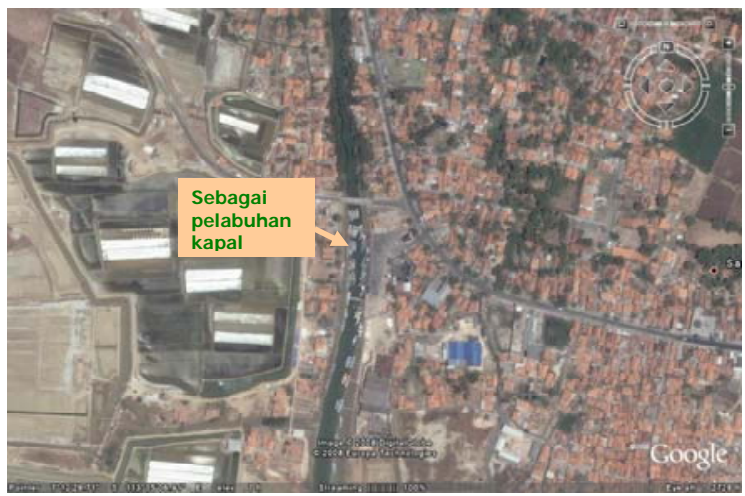

Gambar 1: Situasi Kali Kemuning melalui Kota Sampang dan sebagai pelabuhan

Kali Kemuning merupakan kali yang potensi sebagai penyebab terjadinya banjir di Kota Sampang dan wilayah sekitarnya, oleh karena itu dilakukan studi dan perencanaan pengendaliannya.

Dalam studi ini, analisa kapasitas sungai akan dikaji dengan mempertimbangkan aliran tak tunak (unsteady flow) dimana batas hulu adalah hydrograf banjir, dan batas hilir sungai adalah pengaruh pasang surut air laut

Hasil analisa ini diharapkan dapat memberikan pertimbangan penting dalam rangka pengendalian daya rusak air Kali Kemuning, dan mungkin dapat sebagai pertimbangan pengembangan sumber daya air sungai.

Pemanfaan air sungai yang tepat akan memberikan peningkatan nilai, sebagai contoh untuk kebutuhan sumber air baku irigasi tambak garam, sumber air baku irigasi tambak ikan, sumber air baku irigasi sawah dan lain sebagainya. Pemanfaatan air sungai yang tidak tepat akan berdampak negatif pada lingkungan.

\subsection{Maksud dan Tujuan}

Maksud dibangunnya model numerik 1Dimensi aliran di sungai ini adalah agar dapat melakukan simulasi pemahaman kondisi aliran di sungai, sehingga dalam upaya pengendalian dan pemberdayaan air sungai dapat menghasilkan suatu kondisi yang optimum yang diharapkan.

Tujuannya adalah membangun model perambatan gelombang di sungai dengan methode differensi hingga Skema Staggered Grid dan aplikasinya pada kasus analisa kapasitas sungai Kali Kemuning Sampang Madura.

\section{KAJ IAN PUSTAKA}

Persamaan kontinuitas dan persamaan Momentum aliran masing-masing merupakan persamaan differensial parsial, oleh karena itu penyelesaiannya dilakukan dengan methode numerik.

Wignyosukarto, 1996, telah menyelesaikan dengan baik persamaan kontinuitas dan persamaan Momentum aliran 1-D dengan baik yaitu yang telah dipatenkan dengan nama GamaFLOW-1D, 1995. penyelesaian persamaan kontinuitas dan persamaan Momentum aliran ini telah diselesaikan dengan mehode numeric Skema Karakteristik. Pada artikel ini ditunjukkan penyelesaian persamaan kontinuitas dan persamaan Momentum aliran dengan methode differensi hingga Skema Staggered Grid oleh Suharjoko 2009, dan kemudian dikembangkan aplikasinya pada kasus pemahaman kondisi aliran sungai yang akan disajikan dalam artikel ini. Sebagai penjelasan hasil, diberikan aplikasinya pada kasus perambatan banjir Kali Kemuning Sampang Madura.

\section{METODOLOGI}

Dalam membangun model perambatan gelombang, didahului dengan membangun model aliran. Sehingga dalam membangun model ini dilakukan melalui tahapantahapan sebagi berikut;

Pertama; mendapatkan persamaan kontinuitas dan persamaan momentum sebagai persamaan aliran 1-D, ke dua; penurunan skema numeris persamaan aliran 1-D dengan skema Staggered Grid, ke tiga; penulisan program, ke empat; pengujian dan 
ke lima; aplikasi kasus dilanjutkan dengan pembahasan.

Tahapan-tahapan ini dapat dijelaskan mengikuti skema sesuai pada Gambar 2. berikut.

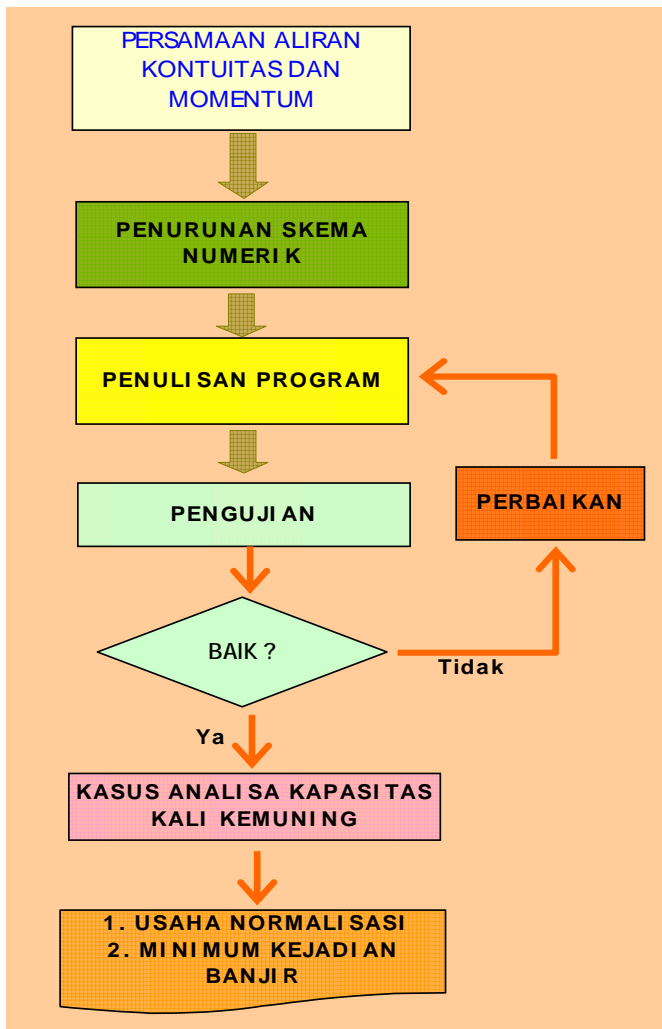

Gambar 2: Tahapan membangun model 1-D Aliran

\section{PENYUSUNAN PROGRAM DAN KALIBRASI 4.1. Persamaan Aliran dan Penurunan Skema Numerik}

Persamaan aliran tak tunak (unsteady flow) adalah persamaan Kontinuitas dan Persamaan Momentum aliran sebagai berikut.

$$
\frac{\partial h}{\partial t}+\frac{1}{B} \frac{\partial}{\partial x}(Q h)=0
$$

dan

$$
\frac{\partial Q}{\partial t}+\frac{\partial}{\partial t}\left(\frac{Q^{2}}{A}\right)+g A \frac{\partial h}{\partial x}-g A\left(S o-S_{f}\right)=0
$$

$\mathbf{Q}=$ debit Aliran

$\mathbf{V}=$ Kecepatan aliran

A = Luas Penampang Basah

$\mathbf{g}=$ Grafitasi

So $=$ Kemiringan Dasar Sungai

$\mathbf{S f}=$ Kemiringan Energi Aliran

Dapat dilihat bawa persamaan aliran tersebut merupakan persamaan deferensial parsial, maka penyelesaiannya harus dilakukan dengan methode numerik, yaitu diselesaikan dengan methode numerik Skema Staggered Grid sebagai berikut;

Pada metode ini menggunakan double jaring hitung, hitungan untuk varibabel unsur $Q$ dan $V$ mengikuti jaring-jaring biasa, yaitu pada hitungan setiap lompatan jarak $\Delta x$ dan lompatan waktu $\Delta$ t. Sedangkan untuk hitungan variable $h$ atau $A$ pada setengah lompatan. Gambar 3. berikut ditunjukkan jaring-jaring hitungan Skema Staggered Grid. Maka dengan skema tersebut dapat diturunkan persamaan numerisnya sebagai berikut;

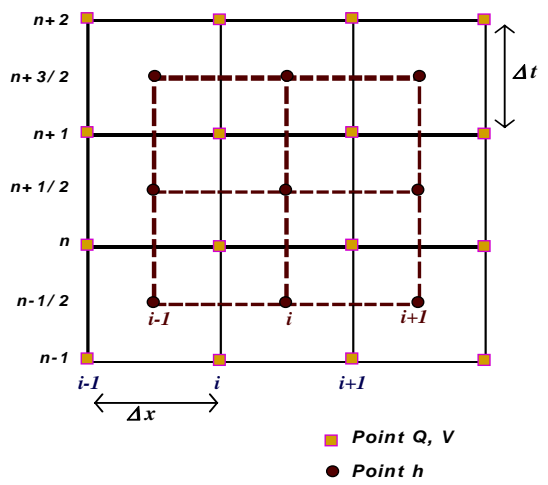

Gambar 3: J aring-jaring hitungan Skema Stegered Grade

$$
\begin{aligned}
h(i+1, j)= & h(i, j)-d t / d x * H R *(q(i, j+1)-q(i, j)) / \\
& B r t(j) \\
q(i+1, j)= & Q R-d t / d x / \operatorname{Brt}(j) *(Q Q 2 \wedge 2 / H H 2- \\
& Q Q 1 \wedge 2 / H H 1)-(g f * D T X * H H * \\
& (H H 2-H H 1)-g f * H H *(S o-S F) * d t) \\
& / \operatorname{Brt}(j)
\end{aligned}
$$

$H R=(h(i, j)+h(i, j+1)) / 2$

$H H 1=(h(i+1, j)+h(i, j)) / 2$

$H H 2=(h(i+1, j+1)+h(i, j+1)) / 2$

$\mathrm{QQ1}=(\mathrm{q}(\mathrm{i}, \mathrm{j})+\mathrm{q}(\mathrm{i}, \mathrm{j}-1)) / 2$

$\mathrm{QQ2}=(q(i, j)+q(i, j+1)) / 2$

$\mathrm{SF}=(\operatorname{Abs}(\mathrm{QR}) * \mathrm{QR}) * \mathrm{n} \wedge 2 /(\mathrm{HH})) \wedge 3.34$

dimana :

J urnal APLIKASI: Media Informasi \& Komunikasi Aplikasi Teknik Sipil Terkini 


\subsection{Penulisan Program}

Dari skema hasil penurunan persamaan aliran di atas maka selanjutnya dilakukan penyusunan program, pada penyelesaian program ini ditulis dalam bahasa Visual Basic, input data ditulis dalam format Excel dan kemudian output program diolah dan diseselaikan dengan program Excel.

\subsection{Kalibrasi Model}

Untuk mendapatkan keyakinan akan validitas program, dilakukan serangkaian test dan langkah sebagai berikut.

a. Pemilihan bilangan Courant Number dengan criteria $(\mathrm{C} \Delta \mathrm{t} / \Delta \mathrm{x})<\mathrm{l}$ dimana

$$
C=\sqrt{\mathrm{gh}}
$$

b. Disipasi numeric, langkah ini dimaksud untuk mendapatkan pemilihan $\Delta \mathrm{x}$ hitungan yang baik, yang menghasilkan menyimpangan paling kecil.

\section{KASUS KAPASITAS KALI KEMUNING 5.1. Kondisi Sungai Kemuning}

Berdasarkan studi terdahulu Kali Kemuning merupakan sungai yang potensi sebagai penyebab terjadinya banjir di Kota Sampang dan sekitarnya. Oleh karena itu telah dilakukan perencanaan pengendalian pada Kali Kemuning. Hasil pengukuran sungai menunjukkan kondisi dasar sungai yang tidak stream line, oleh karena itu dilakukan rencana pelurusan dasar dan tanggul seperti yang dapat dilihat pada Gambar 4. berikut. Kemiringan dasar sungai dari hulu sampai $4,20 \mathrm{~km}$ lo $=0,00004$, sedangkan dari 4,20 $\mathrm{km}$ ke hilir lo $=0,000199$.
Dan berdasarkan kondisi penampang sungai yang ada sesuai hasil pengukuran, normalisasi sungai direncanakan nonuniform, dari hulu hingga $4 \mathrm{~km}$ ke hilir lebar sungai $=25 \mathrm{~m}$. kemudian ke hilir sampai pada $9 \mathrm{~km}$. berangsur-angsur melebar hingga $35 \mathrm{~m}$. kemudian sampai pada $11 \mathrm{~km}$. berangsur-angsur melebar hingga $45 \mathrm{~m}$. dan sampai hilir pada $12 \mathrm{~km}$. berangsur-angsur melebar hingga $55 \mathrm{~m}$.

\subsection{Analisa HECRAS}

Dalam analisa kapasitas sungainya telah dilakukan dengan menggunakan software HECRAS untuk analisa geometri rencana sungai yang menghasilkan debit optomum sebesar Q=290 m3/ dt. Analisa ini mempertimbangan batas hulu merupakan debit aliran continue (steady flow) dan batas hilir adalah elevasi yang tetap dengan kondisi pasang. Hasil hitungan ini memberikan rekomendasi tinggi tanggul sebagaimana yang dapat dilihat pada Gambar 4. berikut ini.

\subsection{Model numerik 1-D Aliran Skema Staggered Grid}

Dalam studi ini akan dikaj i dengan tinjauan mempertimbangkan aliran tak tunak (unsteady flow) dimana aliran masuk di hulu sungai sebagai batas hulu adalah hydrograf banjir, dan dibagian hilir sungai dipengaruhi pasang surut air laut

Dan pada tinjauan kapasitas ini akan dipertimbangkan adanya batas hilir pasang surut dengan tinggi $\mathrm{H}=3.20 \mathrm{~m}$. dan periode pasang surut adalah $12 \mathrm{jam}$, yang diwakili sebagai fungsi sinusoidal.

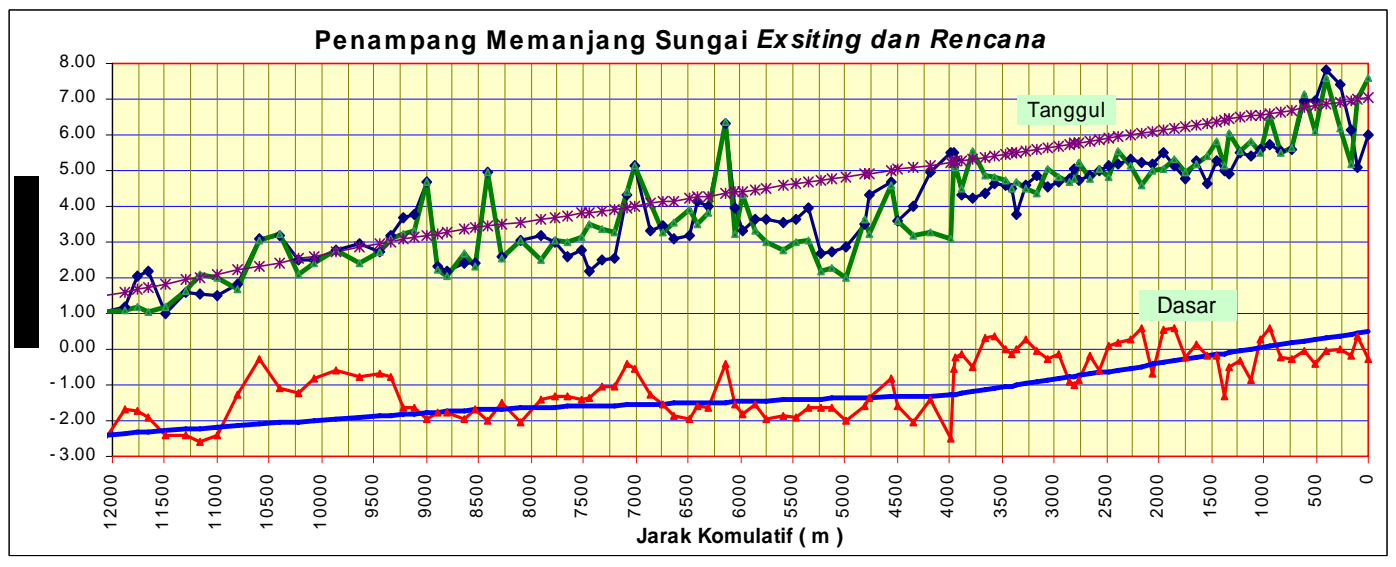

Gambar 4: Hasil pengukuran memanjang sungai dan rencana normalisasi. 
Dengan memberikan batas hulu hydrograf banjir Kali Kemuning yaitu dengan puncak banjir sebesar $300 \mathrm{~m} 3 / \mathrm{dt}$. yang terjadi pada jam ke 3 setelah hujan mulai terjadi.

Kemudian untuk mendapatkan hasil yang baik, dan dengan pertimbangan agar dicapai kondisi yang ekstrim, analisa dilakukan terhadap 4 kasus yang dibedakan oleh kondisi fase pasang surut sementara batas hulu sama antara kasus satu dengan yang lainnya yaitu merupakan hydrograf banjir dengan puncak banjir Qmax $=300 \mathrm{m3} / \mathrm{dt}$, keempat kasus tersebut adalah ;

Kasus 1 fase pasang surut $=0 \mathrm{jam}$, Kasus 2 fase pasang surut $=3 \mathrm{jam}$, Kasus 3 fase pasang surut $=6 \mathrm{jam}$ dan Kasus 4 fase pasang surut $=9 \mathrm{jam}$.

Setelah diselesaikan analisa ( running program ) terhadap empat kasus seperti yang diajukan didepan maka dihasilkan sebagai berikut :

\section{a. Kasus 1, fase pasang surut $=0$ jam.}

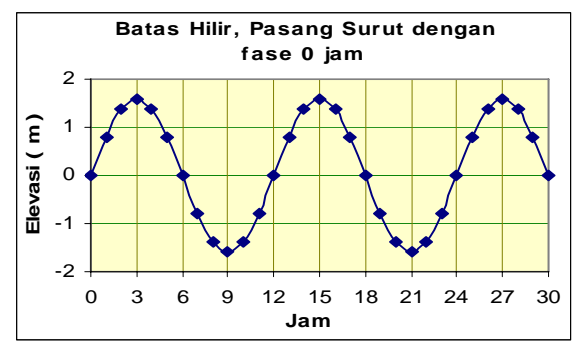

Gambar 5: Fluktuasi Pasang Surut pada fase jam ke 0.00. (Kasus 1.)

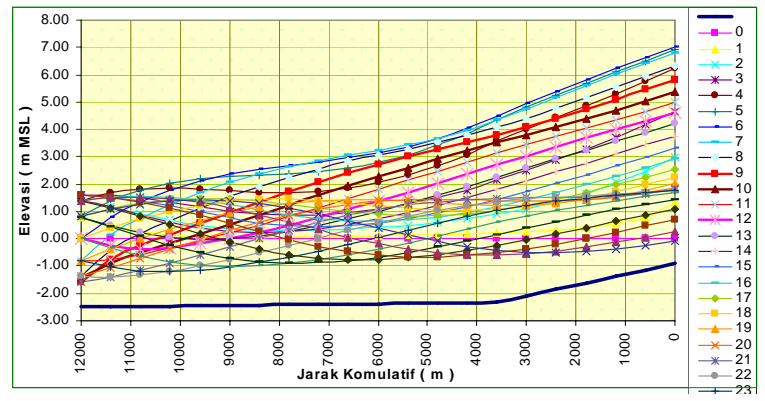

Gambar 6: Muka Air Hasil Simulasi pada Setiap J am Running, dengan Batas Hilir Kasus 1. b. Kasus 2, fase pasang surut $=3$ jam.

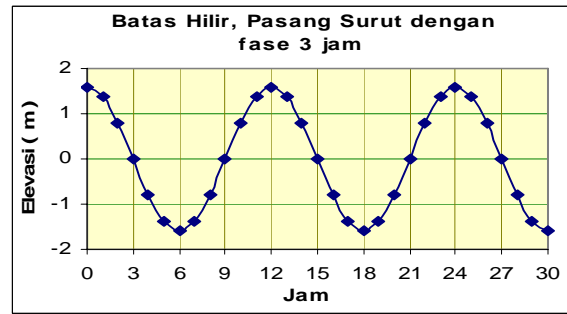

Gambar 7: Fluktuasi Pasang Surut pada fase jam ke 3.00. (Kasus 2.)

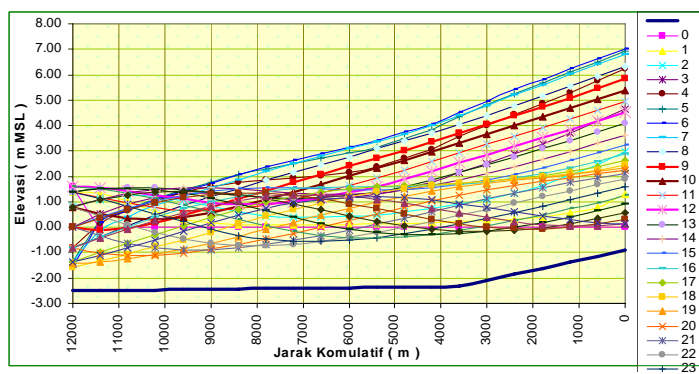

Gambar 8: Muka Air Hasil Simulasi pada Setiap J am Running, dengan Batas Hilir Kasus 2.

c. Kasus 3 fase pasang surut $=6 \mathrm{jam}$

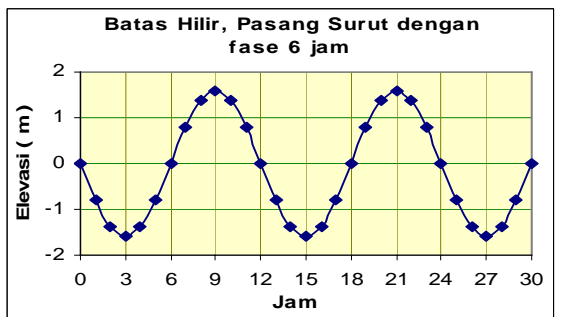

Gambar 9: Fluktuasi Pasang Surut pada fase jam ke 6.00. (Kasus 3.)

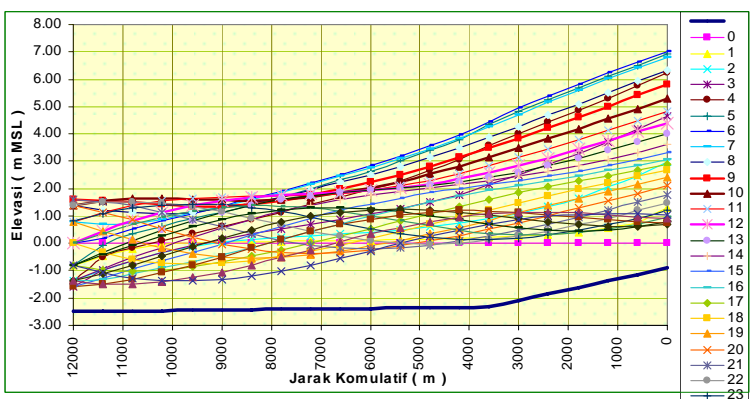

Gambar 10: Muka Air Hasil Simulasi pada Setiap J am Running, dengan Batas Hilir Kasus 3. 


\section{d. Kasus 4 , fase pasang surut $=9$ jam}

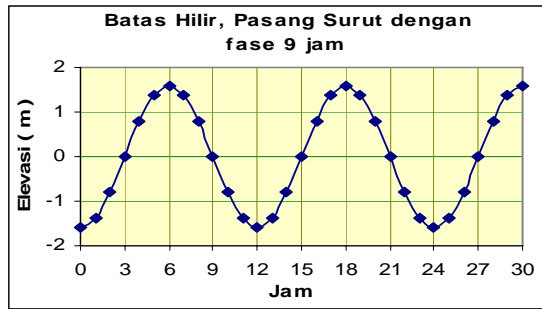

Gambar 11: Fluktuasi Pasang Surut pada fase jam ke 9.00. (Kasus 4 .)

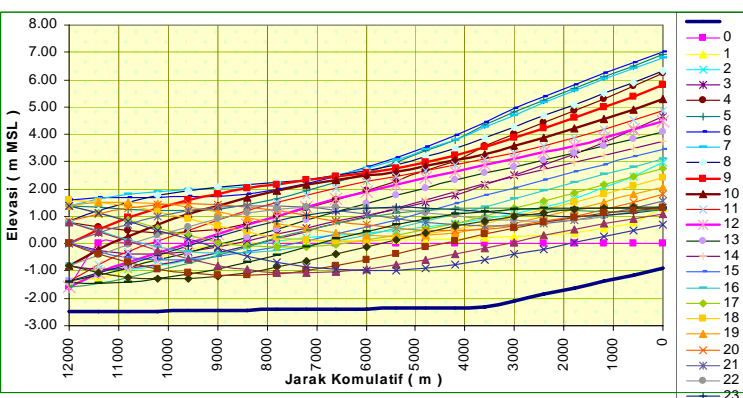

Gambar 12: muka air hasil simulasi pada setiap jam running, dengan batas hilir Kasus 4.

Dari hasil simulasi terhadap ke empat kasus yang dapat dilihat pada Gambar 6, Gambar 8, Gambar 10, dan Gambar 12, diperoleh bahwa muka air yang dihasilkan dari simulasi tersebut pada kasus 2 dan kasus 3 merupakan hasil simulasi aliran model perambatan gelombang di sungai dengan methode differensi hingga Skema Staggered Grid dan aplikasinya pada kasus analisa kapasitas sungai Kali Kemuning. Muka air tertinggi dari hasil simulasi tersebut dijadikan pertimbangan untuk menentukan tinggi tanggul rencana.

Secara umum dapat dirumuskan bahwa hasil simulasi pada rencana normalisasi Kali Kemuning-Sampang Madura, adalah; di muara menunjukkan elevasi muka air tertinggi adalah 1,00 m MSL, pada jarak 6,6 $\mathrm{km}$ dari muara menunjukkan elevasi muka air tertinggi adalah 4, $35 \mathrm{~m}$. MSL, pada jarak $7,8 \mathrm{~km}$ dari muara menunjukkan elevasi muka air tertinggi adalah 4,52 m. MSL dan pada hulu menunjukkan elevasi muka air tertinggi adalah 6,42 m MSL. Jika dibandingkan terhadap rencana normalisasi analisa HECRAS, maka di hilir (muara) elevasi tanggul rencana adalah $2.00 \mathrm{~m}, \mathrm{MSL}$, sehingga perlu dikoreksi sampai pada jarak $2,50 \mathrm{~km}$. Dengan demikian perlu dilakukan dengan memotong tanggul di bagian hilir setinggi 0,5 meter dan berangsur-angsur menipis hingga 0 meter sampai pada jarak $2.50 \mathrm{~km}$ ke arah hulu, lebih jelasnya dapat dilihat pada Gambar 13. berikut.

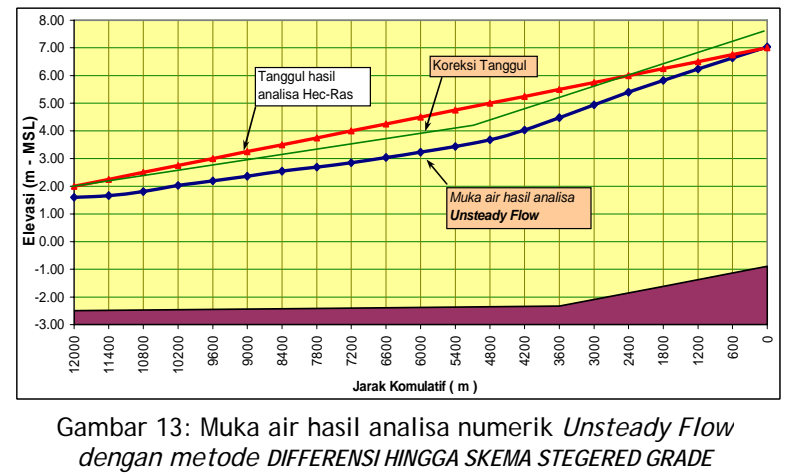

\section{KESIMPULAN}

Hasil pengukuran sungai Kemuning menunjukkan dasar sungai yang ada tidak stream line, oleh karena itu dilakukan rencana pelurusan dasar dan tanggul sebagai berikut; dari hulu sampai $4,20 \mathrm{~km} 10=$ 0,000199 sedangkan dari 4,20 km ke hilir lo $=0,00004$. normalisasi lebar sungai direncanakan non-uniform, dari hulu lebar sungai $=25 \mathrm{~m}$. kemudian ke hilir berangsurangsur melebar hingga $35 \mathrm{~m}$. kemudian melebar hingga $45 \mathrm{~m}$. dan sampai hilir melebar hingga $55 \mathrm{~m}$.

Aplikasi program diberikan batas hilir pasang surut dengan tinggi $\mathrm{H}=2.00 \mathrm{~m}$. dan periode adalah 12 jam, batas hulu hydrograf banj ir Kali Kemuning yaitu dengan puncak banjir sebesar $300 \mathrm{m3} / \mathrm{dt}$. yang terjadi pada jam ke 3 setelah hujan mulai terjadi.

Hasil simulasi telah dapat menggambarkan dengan baik kondisi muka air pada setiap jam di sepanjang sungai.

\section{DAFTAR ACUAN}

Suharjoko dkk , 2008, Survei Investigasi dan Disain Daya Rurak Air Kali Kemuning, Balai Besar Pengairan Brantas. Surabaya.

Suharjoko dkk, 2006, Studi Kajian Run-off Sungai di Jawa Timur, SubDinas Pengairan Dinas PU Propinsi J awa Timur.

Cristoper G Koutitas, 1983, Elemen of Komputational Hydraulics, Pentech Press, London.

Wignyosukarto, Budi, 1995, Model Matematik GamaFLOW - 1D, UGM. 
